\title{
Erratum to: Assessing concrete strength with rebound hammer: review of key issues and ideas for more reliable conclusions
}

\author{
Denys Breysse · Juan Luis Fernández-Martínez
}

Published online: 23 October 2013

(C) RILEM 2013

\section{Erratum to: Materials and Structures DOI 10.1617/s11527-013-0139-9}

Due to an unfortunate turn of events this article was published with an erroneous version of the authors names. Please find on this page the correct version of the authors names that should be regarded by the reader as the final version.

The online version of the original article can be found under doi:10.1617/s11527-013-0139-9.

D. Breysse $(\square)$

UMR 5295, CNRS, I2M, University of Bordeaux,

Talence, France

e-mail: denis.breysse@u-bordeaux1.fr

J. L. Fernández-Martínez

University of Oviedo, Oviedo, Spain 